\title{
Sustainability of the Greek Government Net Borrowing: An Analytical and Comprehensive Exposition
}

\author{
Anna Maria Mouza \\ Department of Business Administration, Technological Educational Institute of Central Macedonia, Serres, \\ Greece \\ Email: annmouza@gmail.com
}

Received 19 June 2016; accepted 12 August 2016; published 15 August 2016

Copyright (C) 2016 by author and Scientific Research Publishing Inc.

This work is licensed under the Creative Commons Attribution International License (CC BY). http://creativecommons.org/licenses/by/4.0/

c) (7) Open Access

\begin{abstract}
This paper aims to investigate the sustainability of the general Greek government net borrowing, applying novel techniques for both to determine the order of integration of a difference stationary series and to specify the final form of the co-integration equation. Co-integration analysis was applied, and robust rules of thumb are suggested taking into account the individuality of the case under consideration. The empirical application revealed that the Greek debt is not sustainable. Further, we introduce consistent planning methods to obtain optimal time paths for both government revenue and spending, so as sustainability of the debt to become a feasible task under certain assumptions. Finally, we suggest a policy making approach on macrolevel combining co-integration with optimal control.
\end{abstract}

\section{Keywords}

Debt Sustainability, Autocorrelation, Homoscedasticity, Co-Integration, Greek Debt

\section{Introduction}

For the budget deficit to be sustainable, the government must run further budget surpluses (expressed in present value terms) equal to the current value of its liabilities. Although policy makers are concerned about the aggravation of budget deficit, economists look at the deficit issue from a different point of view. Instead of emphasizing the size of the deficit at any particular time-instant, they are more concern with the intertemporal budget constrain, which in turn focuses on the long-run path of expenditures and revenues. According to Hakkio [1], temporary current account deficits do not expect to create serious problems as they usually reflect the re-allo- 
cation of capital in the economy for the most productive sectors. On the contrary, persistent current account deficits have an unfavorable effect on the economy under consideration, the most harmful being the imposition of an excessive burden on future generations resulting a lower standard of living since they will have to pay back high amounts of accumulated debts. There are many studies on budget deficit sustainability (see for instance Chen [2]; Hakkio [1]; Hakkio and Rush [3]; Husted [4]; Martin [5]; Quintos [6]; Wu [7], among others). The results are not unified mainly due to the different methodology adopted, the specification of the transversality condition and particularly the sample period used.

In this context and considering some research works for countries where Greece included, Fountas and Wu [8] applied a residual-based co-integration test suggested by Gregory and Hansen [9], to test for the sustainability of Greek fiscal deficits over the period 1958-1992. Camarero, Carrion-i-Silvestre and Tamarit [10] applied cointegration analysis in an attempt to investigate the relationship between debt level and fiscal sustainability in 17 OECD countries, using a sample that extended from 1970 to 2012 in most cases and proceeded to make an excessive reference to various tests. Georgantopoulos and Tsamis [11], as well as Kalou and Paleologou [12], used the VAR approach and particularly the Vector Error Correction Models (VECM) to determine the causal relation between budget deficits and nominal effective exchange rate for the period 1980-2009 in the first case and to examine the causal relation between the budget deficit and the current account deficit using data from 1960 to 2007 in the latter one. Also, Richter and Paparas [13] adopted the typical VAR formulation to identify the direction of the causality between government spending and revenue in Greece for the period 1833-2009.

Greece jointed the European Union (EU) in 1981 and adopted the euro in 2001 since it has achieved fiscal adjustments over the period 1993-1999, regarding the reduction of the general government deficit, the decrease in inflation and interest rates, together with the gradual increase of the primary surplus and GDP. Hence it was expected that Greece would accelerate its real economic growth and the social convergence with the other European countries. In the following years, the Greek economy exhibited an upwards trend, till the US financial crisis of 2008 that hit the world economy and severely affected the most European countries, given that some large financial institutions collapsed, and banks were bailed out by government aid. Although noticeable economic growth characterized Greece over the period 2000-2007, it was fatal that a policy which could not ensure sustainable progress has been adopted. In particular, the growth was based on domestic demand, mainly underpinned by private consumption due to the rising incomes. Besides, low mortgage rates led to the increase in residential investment and consumer credit expansion, resulting in high levels of borrowing both for the public and private sector. It is noted that in contrary to exports of goods and services, imports had an upwards trend contributing thus to the increase of current account deficit and the growth of the Greek general government deficit, in conjunction with the increased levels of public spending and the parallel decrease in revenues (Bank of Greece [14]). On the other hand, the primary surplus started to decline after 2000, and the competitiveness of the country declined rapidly. All these factors significantly affected the Greek economy and resulted in large deficits and high levels of public debt.

In 2009, Eurostat revised the data referred to the Greek budget deficit resulting to a considerable upwards reform revealing thus that the Greek fiscal problem was unexpectedly wider than it was estimated till then (Kouretas and Vlamis [15]). This unfavorable situation led to a confidence deficit of the foreign investors, the parallel downgrading of the economy's credit rating and the constant increase of the spreads between Greek and German government bonds. Additionally, seriously liquidity problems of the banking system emerged, due to the limited availability to borrow from the international interbank market. At that time Greek economy entered into severe recession having an enormous public debt, facing the possibility to default on its debt and to exit the Eurozone (Tsounis and Polychronopoulos [16]). After several consecutive years of economic growth, Greece entered recession in 2009 (see also Betz [17]), with the sovereign bond depreciation and having the highest budget deficit in the EU, when the government net borrowing came up to $16.275 \%$ of GDP.

Under this economic pressure, Greece requested support from its European partners, as to restore sustainable growth. In this context, the European Commission (EC), European Central Bank (ECB) and International Monetary Fund (IMF) provided bailout loan rescue packages in order to help the government to pay its creditors and to straightly cover its operational needs. In return, Greek government signed for each loan a Memorandum of Understanding specifying the required policy measures to achieve a sustainable recovery regarding fiscal and financial sustainability, growth, competitiveness, investment and needed reforms in the public administration. The measures imposed mainly referred to immediate actions, including the decrease of public expenditure and the increase of public revenue via indirect taxes, taxes on luxury goods, firms' profits and the reduce of tax eva- 
sion. Also measures regarding the freeze and cutback of wages and pensions, suspension in recruitment of public sector, abolishment of the 13th and 14th annual salary, privatizations as well as introduction of reforms regarding the benefit system and health care sector, in order to satisfy all requirements for achieving growth, competitiveness, and economic development. Although the imposed program aimed to stabilize the Greek economy, it had a devastating effect on Greece's already weak economic recovery mainly due to the decrease in demand for goods and services, the enormous high rate of unemployment, the inefficient public sector, the reduced level of investments, the existing bureaucracy, the political and economic corruption and the hesitation of the government to undertake decisive reforms due to the political cost incurred. All the above leaded the Greek economy to a more severe recession including capital controls.

It is worthy to mention that some politicians and many rioting Greeks favor country's default and return to the drachma (previous national currency), due to the Greece's economic situation. However, the most efficient initial reaction is to realize the actual cause of this unfavorable situation that makes the future of Greece uncertain. Regarding expenditures mentioned above, it is true that some major public projects have been undertaken, such as the Venizelos International Airport, the Athens metro, the northwest highway known as Egnatia highway, the Rio-Antirio Bridge and other, due to 2004 Olympic Games. It should also be noted that the Olympic Games cost together with improvement infrastructure came up to 15 bill dollars (about 8\% of GDP), although the initially estimated cost was about 6 bill dollars (Lynn [18]).

In 2004, the Greek government faced a financial audit and the debt crisis begun in 2009. Greece was in debt over the entire time-period considered, with a rapid increase starting from 2002, as it is verified from Figure 1, where the (absolute) values of Government Net Borrowing (GNB) in billions are presented ${ }^{1}$. During the period preceding EU entry (1981), the net borrowing gap reduced considerable as Greece attempted to meet up EU entry requirements as mentioned earlier. After that, the borrowing gap followed a smooth increase before rapidly growing in 2008-2009.

Apart from the complicated procedures to trace possible structural breaks of this form which are unknown a priory, a simple rule of thumb is to compute $\triangle G N B_{i}$ and the mean $\overline{G N B}$ from

$$
\Delta G N B_{i}=G N B_{i}-G N B_{i-1}, \quad \overline{G N B}=\sum G N B_{i} / T
$$

where $T$ denotes the number of observation points. When $\triangle G N B_{i}$ is close ${ }^{2}$ to $\overline{G N B}$ and mainly when $\Delta G N B_{i}>\overline{G N B}$, then in many cases a structural shift, particularly when it has a sharp form, can be immediately detected. Here we have: $\overline{G N B}=8.37, \Delta G N B_{2008}=7.95$ and $\Delta G N B_{2009}=12.99$ that tell us a priori what we may expect to see in Figure 1.

This paper aims to investigate the sustainability of the general Greek government net borrowing. Novel techniques have been applied for both to determine the order of integration of a difference stationary series (DSS)

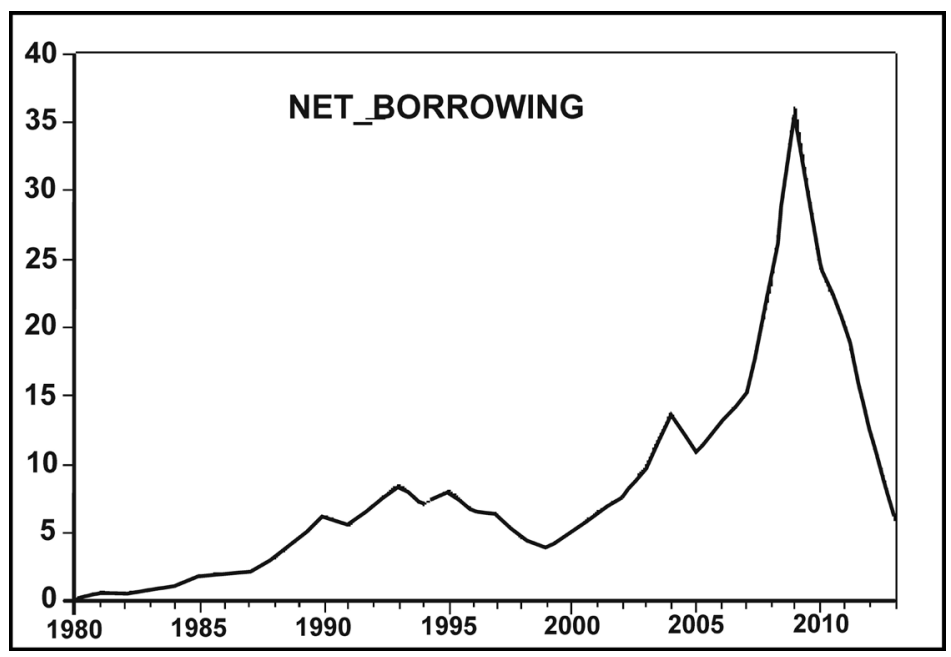

Figure 1. General government net borrowing.

${ }^{1}$ We adopt this International Monetary Fund (IMF) definition, i.e.: General government net borrowing is calculated as revenue minus total expenditure. In this study the terms net borrowing and government debt are interchangeable used to facilitate the discussion.

${ }^{2}$ In some cases the absolute value of these differences should be considered. 
and to analytically specify the final form of the co-integration equation. Finally a proper policy planning is suggested by combining co-integration analysis and optimal control.

In section 2 we graphically present our data and in section 3 we investigate whether the government net borrowing is sustainable with an analytical discussion of the robust procedures adopted both, for determining the order of integration of the time-series considered, together with the relevant co-integration tests. Results together with some further considerations and additional remarks are presented in sections 4,5 and 6 respectively, whereas conclusions are cited in section 7 .

\section{A Framework to Assess Sustainability of Government Net Borrowing}

Following Hakkio and Rush [3], we adopted the regression

$$
R_{i}=a+b G_{i}+u_{i}
$$

that can be viewed as a possible co-integrating relation. In (2) $R_{i}$ denotes government revenue at time-period $i$ ( $i=1980, \cdots, 2013$ ) and $G_{i}$ the corresponding expenditure. Both are expressed as percent of GDP for better capturing the possibility regarding the incentive for the government to default.

If the series $\left\{G_{i}\right\}$ and $\left\{R_{i}\right\}$ have the same order of integration, and they are co-integrated, then the government net borrowing is sustainable, provided that the alternative hypothesis $b<1$ is rejected. The evolution of these series over the time period considered is presented in Figure 2.

It should be recalled at this point that if the order of integration of a DSS series, say $\left\{x_{i}\right\}$, is 1 i.e. $x_{i} \sim I(1)$, then this implies that $\Delta x_{i}$ is stationary, i.e. $\Delta x_{i} \sim I(0)$. If $x_{i} \sim I(2)$, then $\Delta^{2} x_{i} \sim I(0)$. If two series $\left\{x_{i}\right\}$ and $\left\{y_{i}\right\}$, are of the same order of integration, say $I(d)$, then these two series are co-integrated, if the order of integration $\mathrm{m}$ of the OLS residuals $\hat{u}_{i}$ computed after estimating the static relation

$$
y_{i}=b_{1}+b_{2} x_{i}+u_{i}
$$

is $m<d$. It should be emphasized that co-integration ensures long run equilibrium. In general, considering that the two time series are both $I(d)$, then in case that the series $\left\{\hat{u}_{i}\right\}$ obtained from regressing $y_{i}$ on $x_{i}$ is of a lower order of integration, say $I(d-b)$ where $b>0$, then the initial series are co-integrated of order $(d, b)$, which is written as CI $(d, b)$ (Engle and Granger [19]; Lazaridis [20], p. 251).

From Figure 2 we see that the series $\left\{G_{i}\right\},\left\{R_{i}\right\}$ are not stationary. Assuming that both are DSS, we'll see next the way to determine their order of integration.

\section{Methodology}

Our results are derived by properly applying co-integration analysis, taking into account the individuality of the case under consideration. Besides, instead of employing too complicated techniques (see for instance Camarero, Carrion-i-Silvestre and Tamarit [10]; Gregory and Hansen [9]; Hakkio and Rush [3]; Kejriwal and Perron [21]; Lanne, Lütkepohl and Saikkonen [22]; [23]; Shin [24], among others), we provide robust and simple rules of thumb to tackle problems related to this type of analysis. We apply novel and easy to understand techniques for

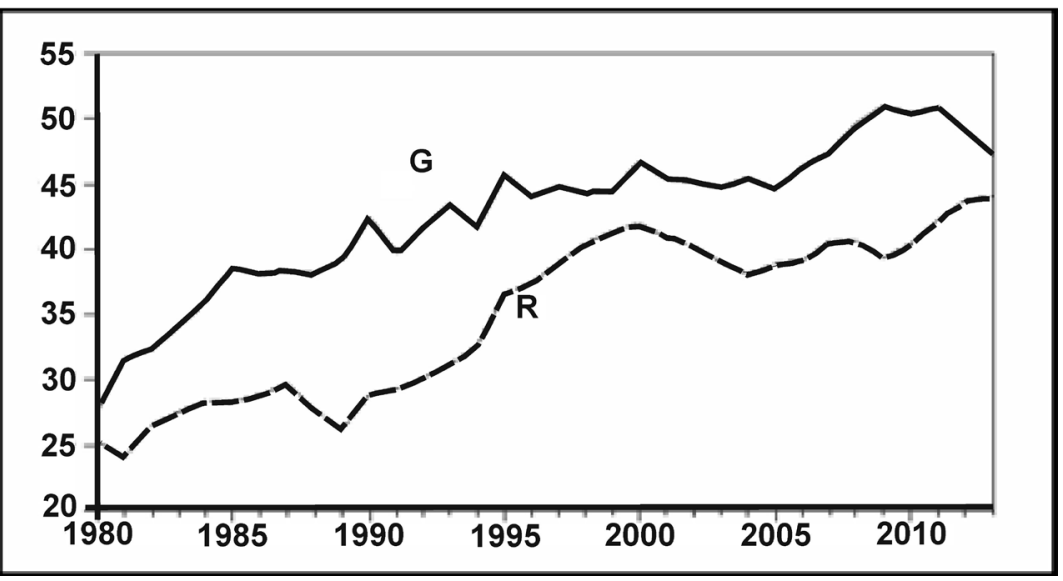

Figure 2. Annual Greek government spending and revenue (percent of GDP). 
both to determine the order of integration of a difference stationary series and to specify the final form of the co-integration equation.

\subsection{Order of Integration}

The fairly new and robust approach proposed by Lazaridis ([20], pp. 273-284) to directly determine the order of integration of a DSS is adopted here. It should be emphasized at the very outset that we don't have to examine first whether the series under consideration is stationary or not searching for a unit root and adopting a test equation with intercept, trend or none of these components. To illustrate this technique, we'll consider the series $\left\{R_{i}\right\}$.

Starting with $n=1$ we estimate the following equation applying OLS.

$$
\Delta^{n} R_{i}=\beta_{1}+\beta_{2} \Delta^{n-1} R_{i-1}+\beta_{3} t_{i}+\sum_{j=1}^{s} \beta_{j+3} \Delta^{n} R_{i-j}+u_{i} .
$$

It is clear that the model in (4) is a re-parametrized AR (q) with intercept, where a trend $\left(t_{i}\right)$ is added. The value of $s$ is so selected to assure that the noise $u_{i}$ is white Gaussian (i.e. non auto correlated, homoscedastic and normally distributed disturbances).

It is noted that for $n=1$ its value is omitted from (4) and that $\Delta^{0} R_{i-1}=R_{i-1}$. Hence, for $n=1$ (4) takes the form:

$$
\Delta R_{i}=\beta_{1}+\beta_{2} R_{i-1}+\beta_{3} t_{i}+\sum_{j=1}^{s} \beta_{j+3} \Delta R_{i-j}+u_{i} .
$$

Next we proceed to test the hypothesis

$$
H_{0}: \beta_{2}=\beta_{3} .
$$

To compare the computed $F$ statistic we have to concern in this case the Dickey-Fuller F-distribution. In Table 1 the relevant critical values (Dickey and Fuller [25]) are presented to facilitate the discussion.

Note that in order to reject (5), $F$ statistic should be much greater than the corresponding critical values seen in Table 1. If we reject (5), this means that the series $\left\{R_{i}\right\}$ is $I(n-1)$. If the null hypothesis is not rejected, we re-estimate Equation (4) increasing the value of $n$ by 1 testing at each step that the noises are white Gaussian.

In our case for $n=1$ and $s=3$ we found

$$
\widehat{\Delta R}_{i}=6.637-\underset{(S E=0.12)}{0.269} R_{i-1}+\underset{(S E=0.07)}{0.162} t_{i}+\sum_{j=1}^{3} \hat{\beta}_{j+3} \Delta R_{i-j} .
$$

Since the lagged dependent variable is among the explanatory variables list, we have to consider statistic $h$, which can't be computed in this case. Note however that the value of DW d is 2.05. The rule of thumb suggested, for being able to say that no autocorrelation exists, is to estimate the autocorrelation function of the residuals $\hat{u}_{i}$ and to consider the Ljung-Box Q statistics, particularly the corresponding $p$-values, which should be much greater than 0.1. The numerical results together with the Box-Pierce Q statistics are presented in Table 2. We observe that all $p$-values of the $5^{\text {th }}$ column of Table 2 are greater than 0.1 which implies that no any autocorrelation problems exist.

A practical way to trace heteroscedasticity is to detect the explanatory variable which yields the smallest $p$-value for the corresponding Spearman's correlation coefficient $r_{s}$, or the greatest (absolute) value of the $Z^{*}$ statistic. It is recalled that $Z^{*}$, which is used when the sample size is large, is computed from

Table 1. Dickey-fuller critical values.

\begin{tabular}{cccc}
\hline Sample size & $\alpha=0.01$ & $\alpha=0.05$ & $\alpha=0.10$ \\
\hline 25 & 10.61 & 7.24 & 5.91 \\
50 & 9.31 & 6.73 & 5.61 \\
100 & 8.73 & 6.49 & 5.47 \\
250 & 8.43 & 6.34 & 5.39 \\
500 & 8.34 & 6.30 & 5.36 \\
$>500$ & 8.27 & 6.25 & 5.34 \\
\hline
\end{tabular}




$$
Z^{*}=\frac{r_{s}}{\frac{1}{\sqrt{(T-1)}}}=r_{s} \times \sqrt{(T-1)}
$$

where $T$ denotes the actual sample size considered during estimation.

In model (6), such a variable is $\Delta R_{i-3}$ resulting to: $r_{s}=0.294, t=1.627, p=0.115$ as it is verified from Table 3 .

Considering the $p$-value we can accept the null (homoscedastic disturbances). As already mentioned, for large samples the statistic $Z^{*}$ is usually employed, and the null is accepted if $\left|Z^{*}\right|<Z_{\alpha / 2}$ (For $\alpha=0.05, Z_{\alpha / 2}=1.96$ ). Even with this test the null is accepted.

Additionally, considering the Jarque-Bera statistic (0.298) and particularly the corresponding $p$-value $(0.86)$, we accept the null (normal residuals, Jarque and Bera [26]).

Thus with $s=3$ (approximately $T^{1 / 3}$ as in Shin's [24], application) we have white Gaussian noises. At this stage, we test (5). Since the value of F-statistic (2.4213) is less than the critical values presented in Table 1, for any level of significance (25 or even 50 observations), we accept (5).

Hence, we increase the value of $n(n=2)$ and repeat the same steps considering the model

$$
\Delta^{2} R_{i}=\beta_{1}+\beta_{2} \Delta R_{i-1}+\beta_{3} t_{i}+\sum_{j=1}^{s} \beta_{j+3} \Delta^{2} R_{i-j}+u_{i} .
$$

With $s=2$, we found that according to the tests described above, the noises are white Gaussian. The value of F-statistic is: 3.35. Thus, the null seeing in (5) is accepted, and we increase once more the value of $n(n=3)$. Now the model to be estimated has the following form.

Table 2. Autocorrelations, PAC, Q statistics and $p$-values which refer to: RESIDUALS.

\begin{tabular}{ccccccc}
\hline Values of $k$ & AC & PAC & Q_Stat. (L-B) & $p$-values & Q_Stat. (B-P) & $p$-values \\
\hline 1 & -0.04014 & -0.04014 & 0.05333 & 0.81737 & 0.04833 & 0.82600 \\
2 & -0.13103 & -0.13286 & 0.64200 & 0.72542 & 0.56341 & 0.75450 \\
3 & 0.03393 & 0.02308 & 0.68292 & 0.87721 & 0.59794 & 0.89690 \\
4 & -0.00437 & -0.01967 & 0.68363 & 0.95333 & 0.59852 & 0.96323 \\
5 & 0.29652 & 0.30925 & 4.05999 & 0.54081 & 3.23630 & 0.66361 \\
6 & -0.24257 & -0.25186 & 6.41369 & 0.37848 & 5.00157 & 0.54361 \\
7 & -0.06193 & 0.02611 & 6.57376 & 0.47456 & 5.11663 & 0.64573 \\
8 & 0.05781 & -0.05110 & 6.71957 & 0.56717 & 5.21687 & 0.73417 \\
9 & -0.26808 & -0.28044 & 10.00491 & 0.35009 & 7.37288 & 0.59836 \\
10 & -0.01144 & -0.11261 & 10.01119 & 0.43951 & 7.37680 & 0.68946 \\
11 & -0.21148 & -0.19415 & 12.27093 & 0.34363 & 8.71852 & 0.64786 \\
12 & 0.05717 & 0.03045 & 12.44524 & 0.41062 & 8.81657 & 0.71851 \\
13 & 0.01587 & -0.08659 & 12.45945 & 0.49038 & 8.82412 & 0.78609 \\
14 & -0.22149 & -0.04492 & 15.40285 & 0.35118 & 10.29582 & 0.74025 \\
\hline
\end{tabular}

\begin{tabular}{|c|c|c|c|c|c|c|}
\hline Indication: & $\Sigma D_{i}^{2}$ & $r_{s}$ coefficient & Stand. error & $t$-statistic & $d f$ & $p$-value \\
\hline Value: & 3174.0 & 0.2939 & 0.1806 & 1.627 & 28 & 0.1149 \\
\hline
\end{tabular}

Table 3. Spearman’s correlation coefficient. 


$$
\Delta^{3} R_{i}=\beta_{1}+\beta_{2} \Delta^{2} R_{i-1}+\beta_{3} t_{i}+\sum_{j=1}^{s} \beta_{j+3} \Delta^{3} R_{i-j}+u_{i} .
$$

With $s=2$ we found that the noises are white Gaussian since the $p$-value of the J-B statistic is 0.099 and the autocorrelation function is analogous to the one presented in Table 2. Trend $\left(t_{i}\right)$ produces the smallest $p$-value for $r_{s}$, that is: $r_{s}=0.228, t=1.22, p=0.233, Z^{*}=1.21$. The value of F-statistic is presented in Table 4 .

We observe that the value of $F(10.318)$ is greater than the corresponding critical values of Table 1 (25 observations) for the level of significance $\alpha=(0.05,0.10)$. This implies that the null i.e. (5) is rejected. In that case the order of integration is $n-1$, i.e. $R_{i} \sim I(2)$ at least for $\alpha=(0.05,0.10)$.

Regarding both series $\left\{R_{i}\right\} \quad\left\{G_{i}\right\}$, in order to detect any possible break before applying the procedure described above, we first adopted the technique proposed by Harvey, Leybourne and Taylor [27]. Although no any structural break for both series has been detected ${ }^{3}$, it is noticeable that we reached the same result even applying the rule of thumb mentioned earlier. Further, we computed at each stage together with the F-statistic, the Hansen's statistics as well as the Cumulative Sums (CUSUM) and Cumulative Sums Squared (CUSUMSQ) statistics to trace any coefficients instability related to a possible shift. None of these tests revealed such instability. For better understanding the latter point we present in Table 5, the values of Hansen's statistics for the last model (8) with $s=2$.

According to Hansen [28], the coefficients instability should be rejected which is an additional supporting indication that no any shift is present. However, in case of a structural break we have to introduce a dummy variable which takes the value 1 at the starting period of the break and zero elsewhere. Following a procedure analogous to the one already described, we add a new unit to the next period, testing at each step that the noises are white Gaussian. If so, we stop adding new unit, and we include the created dummy in the procedure already described above to determine the degree of integration.

Applying the same steps we found that $G_{i} \sim I(2)$ for $\alpha=(0.05,0.10)$. So both series are of the same order of integration. The stationary series $\left\{\Delta^{2} R_{i}\right\},\left\{\Delta^{2} G_{i}\right\}$ are presented in Figure 3 and Figure 4.

\subsection{Co-Integration Tests}

Since both series $\left\{R_{i}\right\},\left\{G_{i}\right\}$ are I (2), the maximum order of integration of the OLS residuals $\hat{u}_{i}$ computed from (2) must not exceed 1 for being able to conclude that the initial series are co-integrated. However, after

Table 4. The final F-statistic.

COLLECTIVE SIGNIFICANCE TEST OF 2 COEFFICIENTS. The value of $F(2,24)$ statistic is $10.318(p=0.0006)$

\begin{tabular}{cc} 
Variables & Coefficient No. \\
\hline$\Delta^{2} R_{t-1}$ & 2 \\
$t$ & 3 \\
\hline
\end{tabular}

\section{Table 5. The Hansen's statistics.}

\begin{tabular}{ccc}
\hline Variables & Estimated coefs. & Hansen statistics \\
\hline$t$ & 0.016944 & 0.057857 \\
$\Delta^{2} R_{i-1}$ & -2.284834 & 0.040101 \\
$\Delta^{3} R_{i-1}$ & 0.651961 & 0.081702 \\
$\Delta^{3} R_{i-2}$ & 0.176969 & 0.078151 \\
Intercept & -0.337598 & 0.065566 \\
\hline
\end{tabular}

${ }^{3}$ For both series the value of the test statistic $t_{\lambda}$ has found less than 2.5 so that the null of no break is accepted for the levels of significance 0.10 and 0.05 . 
estimating (2) we have a strong indication of coefficients instability as it is verified from the corresponding graph seen in Figure 5, which refers to CUSUMSQ statistic, obtained from the recursive residuals graphically presented in Figure 6.

Thus, we have an indication for a possible regime shift as can be verified from the Hansen's statistics presented next. The simplest way to trace the starting point (period) is to combine the indications provided by the two graphs presented in Figure 5 and Figure 6. It can be traced that most probably a shift is anticipated in 1994.

As already mentioned, the coefficients instability can be analytically traced from the Hansen's statistics presented in Table 6.

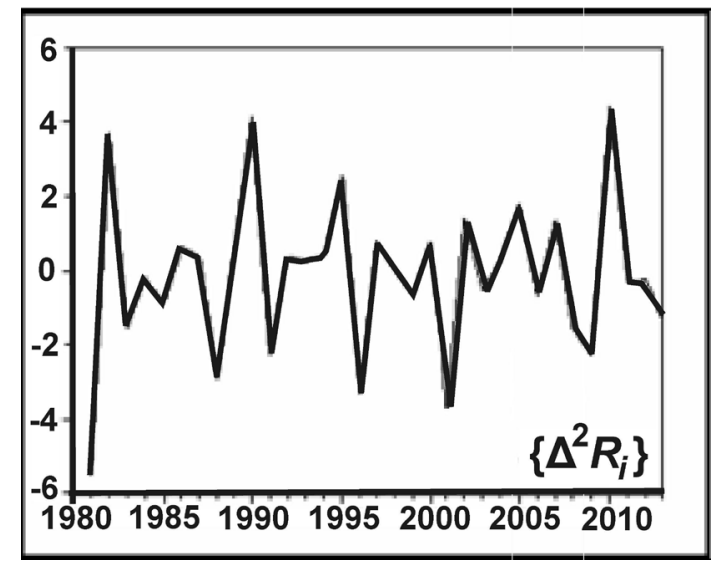

Figure 3. The stationary series $\left\{\Delta^{2} R_{i}\right\}$.

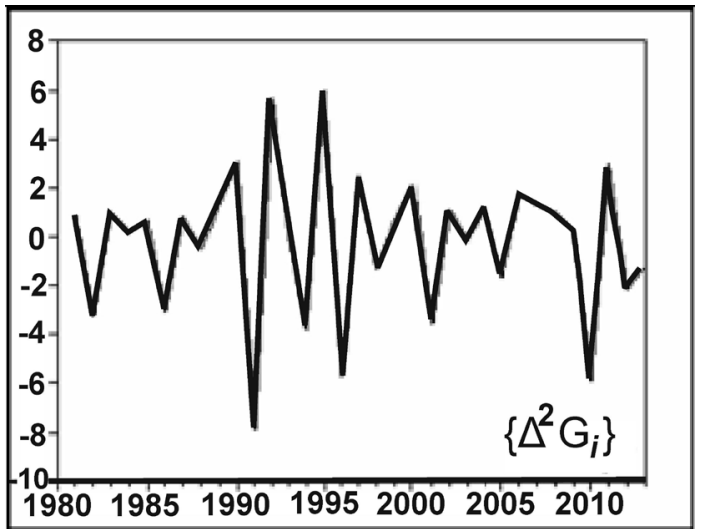

Figure 4. The stationary series $\left\{\Delta^{2} G_{i}\right\}$.

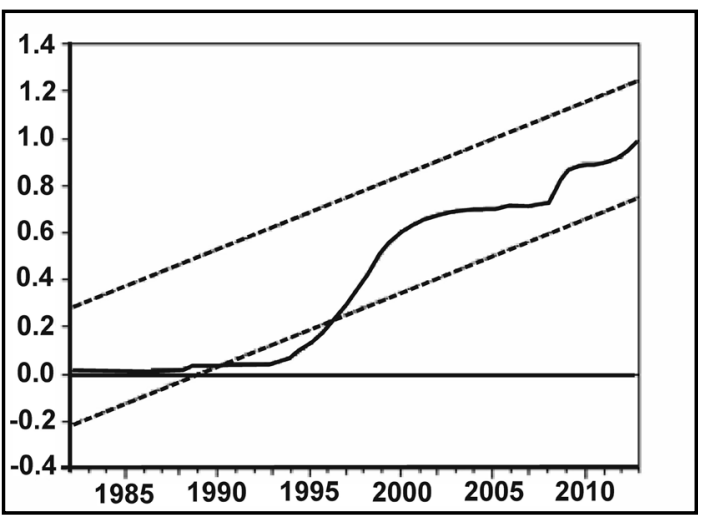

Figure 5. QUSUMSQ statistic. 
Given that the critical value for $\alpha=0.05$ to test the coefficients individually is 0.47 , and to test them collectively is 0.749 , we can conclude that the coefficients instability detected may be due to a possible regime shift. The easiest way to face it is the introduction of a dummy variable $\left(D_{i}\right)$ in (2), which at the very beginning has the value of 1 in 1994 and zero elsewhere. Before adding a new unit for 1995 and so forth we test that the following prerequisites are collectively satisfied.

- The coefficient of the newly introduced dummy is significant.

- The CUSUMSQ test together with the values of Hansen's statistics don't reveal any instability problem, and the value of J-B statistic favors the null (normality).

For the finally specified model all these are satisfied as can be verified from Figure 7 and Table 7.

It is noted that in many cases CUSUMSQ statistic is more sensitive than the corresponding CUSUM, and this is the reason for considering the first one.

With all these in mind, the dummy we finally introduced in (2), has the value of 1 for the years 1994 up to 2013 and the value of zero elsewhere. The estimation results are presented next.

$$
\hat{R}_{i}=\underset{(S E=3.4249)}{15.3593}+\underset{(S E=0.0906)}{0.3394} G_{i}+\underset{(S E=1.1092)}{8.5934} D_{i} .
$$

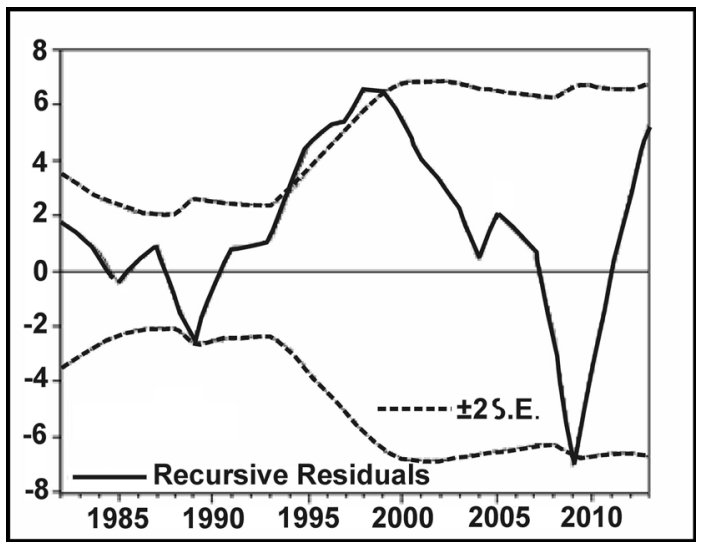

Figure 6. Recursive residuals which refer to Equation (2).

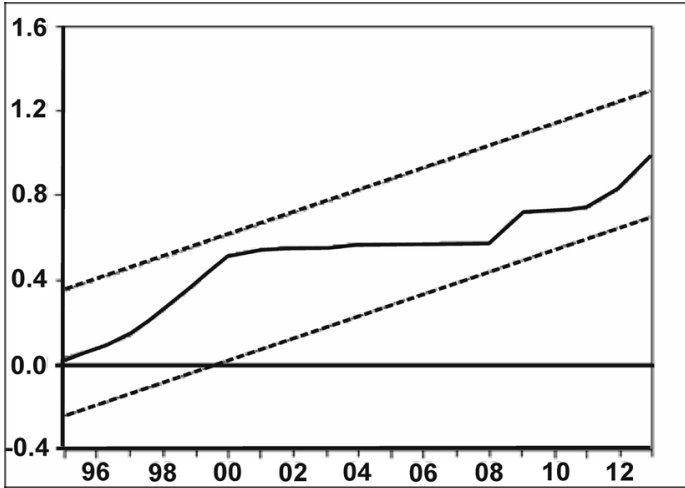

Figure 7. QUSUMSQ statistic computed from the recursive residuals of (9).

Table 6. Hansen's statistics which refer to Equation (2).

\begin{tabular}{|c|c|c|}
\hline Variables & Estimated coefs. & Hansen statistics \\
\hline$G$ & 0.905046 & 0.483212 \\
\hline Intercept & -3.821562 & 0.527181 \\
\hline \multicolumn{2}{|c|}{ General Hansen statistic for all coefficients } & 0.899867 \\
\hline
\end{tabular}


The CUSUMSQ statistic and the J-B and Hansen's statistics are showed in Figure 7 and Table 7 respectively, as mentioned above.

Since the critical value for $\alpha=0.05$ to test all coefficients stability collectively is 1.010 , it is evident from Table 7 that no any instability problem is present anymore.

It is constructive to mention at this point, that in some cases more than one dummy variable must be introduced to the initial regression (2) following the same steps as described above. In any case, it is worthy to emphasize that according to the procedure analytically presented here, it is not necessary to divide the initial sample into sub-samples (see for instance Bajo-Rubio, Díaz-Roldán and Esteve [29]), since in cases with limited observation points, as the one considered here, obvious problems will be raised.

Model (9) has been estimated applying OLS and then we obtained the series $\left\{\hat{u}_{i}\right\}$. These OLS residuals are presented in Table 8.

Applying all conventional tests, we found that the order of integration of the series $\left\{\hat{u}_{i}\right\}$ is less than 2 . This implies that the initial series $\left\{R_{i}\right\},\left\{G_{i}\right\}$ are co-integrated.

Further, we have to perform some significance tests. Regarding the residuals presented in Table 8, the p-value of the J-B statistic is greater than 0.2, as seen in Table 7, which implies that we have to accept the null (normality). Besides, the regression considered is not a spurious one, and hence we believe that the conventional t-tests can be directly applied without any relevant adjustment (see for instance West [30]).

From the estimation results seeing in (9), it is clear that the coefficient of $G_{i}$ i.e. $b$, is highly significant $(p=$ 0.0 ). Thus, we reject the null $H_{0}: b=0$ and accept the alternative $H_{1}: b \neq 0$. However, we are interested in

Table 7. J-B and Hansen's statistics which refer to (9).

\begin{tabular}{|c|c|c|}
\hline Variables & Estimated coefs & Hansen statistics \\
\hline$D$ & 8.593422 & 0.161131 \\
\hline$G$ & 0.339396 & 0.132500 \\
\hline Intercept & 15.35933 & 0.143715 \\
\hline \multicolumn{2}{|c|}{ General Hansen statistic for all coefficients } & 0.754934 \\
\hline \multicolumn{2}{|c|}{ Jarque-Bera statistic } & 2.615378 \\
\hline \multicolumn{2}{|c|}{$p$-value } & 0.270444 \\
\hline
\end{tabular}

Table 8. The OLS residuals $\hat{u}_{i}$ computed from (9).

\begin{tabular}{cccccc}
\hline$i$ & $\hat{u}_{i}$ & $i$ & $\hat{u}_{i}$ & $i$ & $\hat{u}_{i}$ \\
\hline 1 & 0.509661 & 13 & 0.634294 & 25 & -1.305775 \\
2 & -2.013371 & 14 & 1.023527 & 26 & -0.126511 \\
3 & 0.274069 & 15 & -5.457256 & 27 & -0.205329 \\
4 & 0.672840 & 16 & -2.798439 & 28 & 0.619239 \\
5 & 0.812143 & 17 & -1.477005 & 29 & -0.4592285 \\
6 & -0.160461 & 18 & -0.208771 & 30 & -3.939049 \\
7 & 0.563721 & 19 & 1.507164 & 31 & -1.651150 \\
8 & 1.369938 & 20 & 2.324970 & 32 & 0.683041 \\
9 & -0.552626 & 21 & 3.186874 & 33 & 2.810177 \\
10 & -2.450771 & 22 & 1.570400 & 34 & 4.059738 \\
11 & -1.177298 & 23 & 0.979912 & & \\
12 & 0.494329 & 24 & -0.113010 & & \\
\hline
\end{tabular}


testing the hypothesis $H_{0}: b=0$ against the alternative $H_{1}: b>0$ which is one-sided. In this case, we accept $H_{1}$ if

$$
t=\frac{\hat{b}}{S E(\hat{b})}>t_{(\alpha, d f)}
$$

where the second part of the inequality is the critical value of t-statistic for certain level of significance $\alpha$ and 31 degrees of freedom $(d f)$. For $\alpha=0.05, t_{(0.05,31)}=1.69552$. From (9) we can easily find that the value of $t$ equals 3.746. Thus, we accept that $b>0$. This test may seem redundant but strictly speaking it has its own merit.

The most crucial step is to test the hypothesis $H_{0}: b=1$, against the alternative $H_{1}: b<1$, which is also one-sided. In this case, the null is rejected, and we accept $H_{1}$ if:

$$
t=\frac{\hat{b}-1}{S E(\hat{b})}<-t_{(\alpha, d f)} .
$$

Since $t=-7.29$ is less than the critical value -1.69552 , we finally accept that for $\alpha=0.05$ :

$$
0<b<1 \text {. }
$$

It should be emphasized that all these tests refer to coefficient $b$ and not to its estimate $\hat{b}$ as cited in some relevant studies (see for instance Bajo-Rubio, Díaz-Roldán and Esteve [29]; Camarero, Carrion-iSilvestre and Tamarit [10]; Hakkio and Rush [3]). It is also noted that the crucial alternative $\left(H_{1}: b<1\right)$ is not mentioned in some empirical works (see for instance Habib, Rehman, Zafar and Mahmood [31]).

Finally, due to (11) we can say that the debt is not sustainable but we have the weak form of deficit sustainability as defined by Quintos [6]. Obviously, the accumulated deficit will additionally increase total debt. The finding that the debt is not sustainable is in line with the recent issue of the IMF.

It was mentioned earlier that Fountas and $\mathrm{Wu}$ [8] applying a residual-based co-integration test suggested by Gregory and Hansen [9], end up with the same issue that Greek deficit is no sustainable. In Camarero, Carrion-i-Silvestre and Tamarit [10], we read that fiscal policy in Greece was sustainable after 1997, although in a previous place it is stated that the fiscal policy was unsustainable after 1983. It is not entirely clear where these issues are based upon. Even the order of integration of the variables in the co-integration equation is not clearly exposed in all cases, due to the fact that the followed procedure is not unified.

\section{Results}

Applying the procedure analytically presented here, we found that the empirical findings do not satisfy the strong form of deficit sustainability defined by Quintos [6]. Instead, we have the weak form which is verified from (11). It should be noted that $b<1$ provides incentives for the government to default on its debt. In this sense co-integration of $\left\{R_{i}\right\}$ and $\left\{G_{i}\right\}$ would still imply unsustainable fiscal policy as long as $b<1$. This verification makes clear that any positive step is strictly related to the quality improvement of the domestic production. Certainly this implies an amendment in competitiveness which can be based on productivity improvement through technological upgrade. Thus it will be necessary to probe further the need for policies which can increase competitiveness and stimulate growth (Kalou and Paleologou [12]). However, in the short-run a most substantial recovery that can improve debt situation relies on a type of European financed support for public investment in the country, provided that these programs will be supervised by EU authorities to avoid any form of extravagancy. Also, a radical reform of the public sector is of vital importance.

According to our empirical findings it is evident and very encouraging that EU entry did not substantially contribute to the Greek crisis, neither the fact that Greece joined the euro area in 2001. Instead, we can say that the general elections of 1996 contributed to an increase in Greek government spending since the government started from 1994 to increase any provisions, benefits and allowances mainly to its voters, something that is a common practice for almost all governments in Greece. Further the finance of large public infrastructure projects, already mentioned, contributed to the unsustainable Greek deficit. Also, military expenditures (as percent of GDP) begun to rise again from 1994 with a pick at 2000 (about 3.6\%), having a proportional contribution to the government's deficit.

It is recalled that in the co-integrating equation, $R_{i}$ and $G_{i}$ are expressed as percent of GDP. If we consider 
the levels of these variables as we did to compute the debt presented in Figure 1, and re-estimate Equation (9) we'll get the following graph (Figure 8) which refers to the QUSUMSQ statistic.

Observing Figure 8 we can say that in 2004 another possible shift may probably be identified. Indeed, that was the year of general elections. Also, in 2005 the most costly bank recapitalization (18.4 billion Euros) was under way.

It may be constructive to recall at this point that the QUSUM and QUSUMSQ statistics are computed from the recursive residual. The number of these residuals is equal to the number of the observation points minus $(m+q)$, where $m$ denotes the model coefficients and $q(\geq 0)$ is the number of possible singular bases detected and thus the observations to be skipped in the computational process (see the numerical example in Lazaridis [20], pp. 78-79). That is why the horizontal axis of Figure 5 and Figure 6 defers from the corresponding one of Figure 8, since in the latter case $q$ is much larger. This also applies to Figure 7. In that case apart from the value of $q$, the number of model coefficients $m$ is not the same.

\section{Further Considerations}

Using the levels of $R_{i}$ and $G_{i}$ we found that the average annual rate of increase is $12.02029 \%$ for the first one and $11.95116 \%$ for the second. It is recalled that used is made of the formula

$$
R_{2013}=R_{1980}(1+r)^{T}
$$

regarding revenue, where $r$ multiplied by 100 denotes the mean annual rate mentioned above.

After many experiments aiming to obtain a feasible solution assuring sustainability of the debt and avoiding at the same time any radical distortion of the observed mean annual rates we end up to the following issue: Increasing the annual mean rate of $R_{i}$ by 0.005 , i.e. $0.5 \%$ that is from 0.1202029 to 0.12522025 and simultaneously decreasing the corresponding rate of $G_{i}$ by 0.003 , i.e. $0.3 \%$ that is from 0.1195116 to 0.1165116 will have a much smoother evolution of both series. Considering these optimal trajectories and following the steps analytically described earlier we found that the value of $t$ in (10a) is

$$
t=\frac{1.123124-1}{0.048206}=2.55 \text {. }
$$

Since $2.55>-1.69552$ we accept the null i.e. $H_{0}: b=1$, which implies that the debt is sustainable since the series considered are co-integrated.

We strongly believe that this is the basic rule to face the problem of debt sustainability. In this context, the decision makers have to first define the optimal trajectories of both $R_{i}$ and $G_{i}$ to assure sustainability of the debt. The second step is to make these trajectories feasible, properly adjusting the government policy (monetary, fiscal, etc. ${ }^{4}$. Obviously, some reforms may be required, and these should be considered as the major topics for bargaining

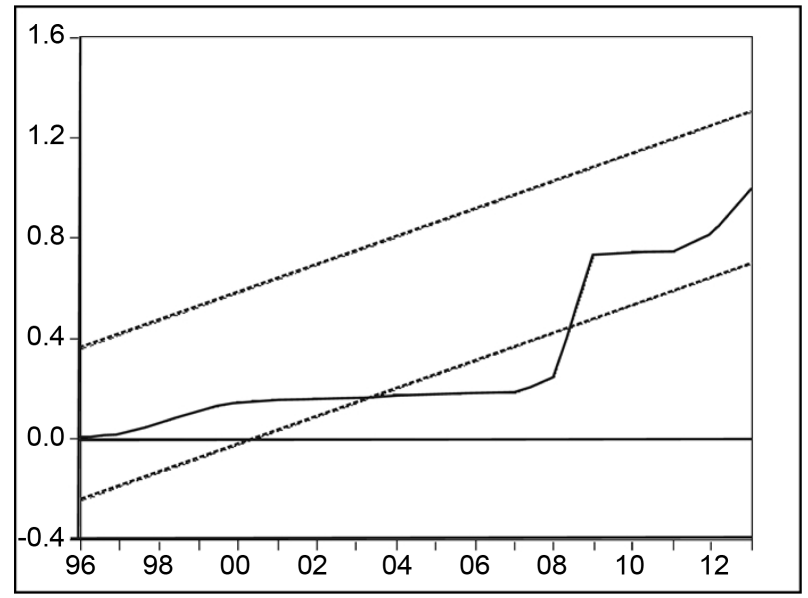

Figure 8. QUSUMSQ Statistic when levels of variables are used to estimate (9).

${ }^{4}$ Selling of some country's assets may be also considered. 
and negotiation with the EU and IMF authorities. In this context, optimal control can be applied to provide detailed numerical indications regarding the measurements required to retain these trajectories for $R_{i}$ and $G_{i}$ that assure sustainability of the debt. This attempt however presupposes the existence of a proper and consistent econometric model of the Greek economy, which can be transferred to an equivalent first order discrete time controllable system ${ }^{5}$. In brief, the most efficient planning over a predefined planning horizon for say $\mathrm{N}$ years is summarized in what follows.

- Determine the average annual rates of increase for both revenue and expenses so that the series $\left\{R_{i}\right\},\left\{G_{i}\right\}$ to be co-integrated in such a way that the alternative $b<1$ to be rejected. These time-paths for the two series are going to be the nominal paths in a relevant control problem, like the one described by Lazaridis ([20], pp. 326-366).

- Solve the optimal control problem to obtain analytical indications for every time-period regarding the measures required to attain the desired paths mentioned above in the closest possible way.

- In case that the measures required can be afforded, then the problem of making the debt sustainable has been solved.

- If the measures required to make feasible the optimal paths are unattainable, and a possible haircut or debt restructuring cannot be considered, then it is inevitable for the government to default on its debt.

\section{Additional Remarks}

Going through the relevant works on this subject, one gets the impression that a ready-made standardized formula has been adopted in many cases. In other words, in most of the works known to the author, a conventional style of co-integration analysis is adopted, that is the variables in the co-integration equation are all I (1), and applying the Dickey-Fuller [32] test it is stated that the residuals are I (0), so that the conclusion of co-integrated series is easily reached, even though the DF/ADF test is not the most appropriate one to confirm residuals stationarity (Harris [33] pp. 54-55, Lazaridis [20], p. 205).

In this context we mention that Shin [24] tests the null of co-integration, using a single equation model with I (1) variables. Fountas and Wu [8] are examining whether the Greek budget deficit is too large, using a single equation model with I (1) variables. Additionally, it is questionable that we haven't met in the relevant works even a single economy where the series in the co-integrating equation are of different order of integration, or their order of integration is greater than 1. One exceptional case is the work of Abeysinghe and Jayawickrama [34] where detection of fiscal sustainability is based upon a relevant model developed by Hamilton and Flavin [35]. Considering the model presented by Abeysinghe and Jayawickrama [34], fiscal sustainability can be assumed if certain coefficients are $\leq 0$. Further, we haven't traced in relevant works, as the ones mentioned earlier, the presentation of any statistical tests to assure coefficients stability of the finally adopted co-integration equation.

\section{Conclusions}

This paper aims to examine as to whether general Greek government net borrowing is sustainable, applying novel, simple and easy to understand techniques for both to determine the order of integration of a difference stationary series and to specify the final form of the co-integration equation. We have analytically presented the case where the series considered are not I (1) as assumed in most relevant studies and analyzed the methodology to find the answer as to whether the Greek debt is sustainable by applying co-integration analysis in conjunction with suggested robust rules of thumb. According to our findings, we can conclude that the Greek government debt is not strongly sustainable, since we face the weak form of sustainability.

In addition, some propositions are clearly stated as to whether this debt can be finally turned up to become sustainable under certain assumptions. In this sense, we introduce consistent planning methods to obtain optimal time paths for both government revenue and spending, so as sustainability of the debt to become a feasible task. Finally, we suggest a policy making approach on macrolevel combining co-integration with optimal control.

The only limitation of this study refers to the moderate size of the available sample. The period 1980-2013 however, is characterized by some significant macroeconomic, political and social reforms leading to a more open, integrated and hence more globalized Greek economy. With this in mind, our intention was to propose an efficient method we haven't met in the relevant literature, based on a reliable sample obtained from IMF [36].

${ }^{5}$ Controllability ensures that the discrete time system under consideration can be transferred from a given initial state to a desired final state in a finite number of time intervals, regardless if it is stable or not. 


\section{References}

[1] Hakkio, C.S. (1995) The US Current Account: The Other Deficit. Economic Review, Federal Reserve Bank of Kansas City, Vol. 80, 11-24.

[2] Chen, S.W. (2011) Are Current Account Deficits Really Sustainable in the G-7 Countries? Japan and the World Economy, 23, 190-201. http://dx.doi.org/10.1016/j.japwor.2011.04.002

[3] Hakkio, C.S. and Rush, M. (1991) Is the Budget Deficit “Too Large?” Economic Inquiry, 29, 429-445. http://dx.doi.org/10.1111/j.1465-7295.1991.tb00837.x

[4] Husted, S. (1992) The Emerging US Current Account Deficit in the 1980s: A Cointegration Analysis. The Review of Economics and Statistics, 74, 159-166. http://dx.doi.org/10.2307/2109554

[5] Martin, G.M. (2000) US Deficit Sustainability: A New Approach Based on Multiple Endogenous Breaks. Journal of Applied Econometrics, 15, 83-105. http://dx.doi.org/10.1002/(SICI)1099-1255(200001/02)15:1<83::AID-JAE543>3.0.CO;2-J

[6] Quintos, C.E. (1995) Sustainability of the Deficit Process with Structural Shifts. Journal of Business \& Economic Statistics, 13, 409-417.

[7] Wu, J.L. (1998) Are Budget Deficits “Too Large”?: The Evidence from Taiwan. Journal of Asian Economics, 9, 519528. http://dx.doi.org/10.1016/S1049-0078(99)80101-8

[8] Fountas, S. and Wu, J.L. (1996) Are the Greek Budget Deficits too Large? Applied Economics Letters, 3, 487-490. http://dx.doi.org/10.1080/758540812

[9] Gregory, A.W. and Hansen, B.E. (1996) Residual-Based Tests for Cointegration in Models with Regime Shifts. Journal of Econometrics, 70, 99-126. http://dx.doi.org/10.1016/0304-4076(69)41685-7

[10] Camarero, M., Carrion-i-Silvestre, J.L. and Tamarit, C. (2015) The Relationship between Debt Level and Fiscal Sustainability in Organization for Economic Cooperation and Development Countries. Economic Inquiry, 53, 129-149. http://dx.doi.org/10.1111/ecin.12126

[11] Georgantopoulos, A.G. and Tsamis, A.D. (2011) The Macroeconomic Effects of Budget Deficits in Greece: A VARVECM Approach. International Research Journal of Finance and Economics, 79, 100-112.

[12] Kalou, S. and Paleologou, S.M. (2012) The Twin Deficits Hypothesis: Revisiting an EMU Country. Journal of Policy Modeling, 34, 230-241. http://dx.doi.org/10.1016/j.jpolmod.2011.06.002

[13] Richter, C. and Paparas, D. (2013) Tax and Spend, Spend and Tax, Fiscal Synchronisation or Institutional Separation? International Network for Economic Research, Working Paper 2013.01.

[14] Bank of Greece (2014) The Chronicle of the Great Crisis: The Bank of Greece 2008-2013. Bank of Greece, Greece.

[15] Kouretas, G.P. and Vlamis, P. (2010) The Greek Crisis: Causes and Implications. Panoeconomicus, 57, 391-404. http://dx.doi.org/10.2298/PAN1004391K

[16] Tsounis, N. and Polychronopoulos, G. (2015) Institutional Changes in the Euro-Zone and the Greek Debt Crisis. SouthEastern Europe Journal of Economics, 12, 145-166.

[17] Betz, F. (2014) Disequilibrium Pricing-Greek Euro Crisis. Theoretical Economics Letters, 4, 897-909. http://dx.doi.org/10.4236/tel.2014.49113

[18] Lynn, M. (2010) Bust: Greece, the Euro and the Sovereign Debt Crisis. John Wiley \& Sons, Hoboken.

[19] Engle, R.F. and Granger, C.W. (1987) Co-Integration and Error Correction: Representation, Estimation, and Testing. Econometrica: Journal of the Econometric Society, 55, 251-276. http://dx.doi.org/10.2307/1913236

[20] Lazaridis, A. (2015) Dynamic Systems in Management Science. Design, Estimation and Control. Palgrave Macmillan, UK. http://dx.doi.org/10.1057/9781137508928

[21] Kejriwal, M. and Perron, P. (2010) Testing for Multiple Structural Changes in Cointegrated Regression Models. Journal of Business \& Economic Statistics, 28, 503-522. http://dx.doi.org/10.1198/jbes.2009.07220

[22] Lanne, M., Lütkepohl, H. and Saikkonen, P. (2002) Comparison of Unit Root Tests for Time Series with Level Shifts. Journal of Time Series Analysis, 23, 667-685. http://dx.doi.org/10.1111/1467-9892.00285

[23] Lanne, M., Lütkepohl, H. and Saikkonen, P. (2003) Test Procedures for Unit Roots in Time Series with Level Shifts at Unknown Time. Oxford Bulletin of Economics and Statistics, 65, 91-115. http://dx.doi.org/10.1111/1468-0084.00036

[24] Shin, Y. (1994) A Residual-Based Test of the Null of Cointegration against the Alternative of No Cointegration. Econometric Theory, 10, 91-115. http://dx.doi.org/10.1017/S0266466600008240

[25] Dickey, D.A. and Fuller, W.A. (1981) Likelihood Ratio Statistics for Autoregressive Time Series with a Unit Root. Econometrica: Journal of the Econometric Society, 49, 1057-1072. http://dx.doi.org/10.2307/1912517

[26] Jarque, C.M. and Bera, A.K. (1987) A Test for Normality of Observations and Regression Residuals. International 
Statistical Review/Revue Internationale de Statistique, 55, 163-172. http://dx.doi.org/10.2307/1403192

[27] Harvey, D.I., Leybourne, S.J. and Taylor, A.R. (2009) Simple, Robust, and Powerful Tests of the Breaking Trend Hypothesis. Econometric Theory, 25, 995-1029. http://dx.doi.org/10.1017/S0266466608090385

[28] Hansen, B.E. (1992) Testing for Parameter Instability in Linear Models. Journal of Policy Modeling, 14, 517-533. http://dx.doi.org/10.1016/0161-8938(92)90019-9

[29] Bajo-Rubio, O., Díaz-Roldán, C. and Esteve, V. (2010) On the Sustainability of Government Deficits: Some LongTerm Evidence for Spain, 1850-2000. Journal of Applied Economics, 13, 263-281. http://dx.doi.org/10.1016/S1514-0326(10)60012-8

[30] West, K.D. (1988) Asymptotic Normality, When Regressors Have a Unit Root. Econometrica: Journal of the Econometric Society, 6, 1397-1417. http://dx.doi.org/10.2307/1913104

[31] Habib, A., Rehman, J.U., Zafar, T. and Mahmood, H. (2016) Does Sustainability Hypothesis Hold in Developed Countries? A Panel Co-Integration Analysis. Quality \& Quantity, 50, 1-25. http://dx.doi.org/10.1007/s11135-014-0134-4

[32] Dickey, D.A. and Fuller, W.A. (1979) Distribution of the Estimators for Autoregressive Time Series with a Unit Root. Journal of the American Statistical Association, 74, 427-431.

[33] Harris, R.I. (1995) Using Cointegration Analysis in Econometric Modelling. Vol. 82, Prentice Hall, London.

[34] Abeysinghe, T. and Jayawickrama, A. (2013) A Segmented Trend Model to Assess Fiscal Sustainability: The US Experience 1929-2009. Empirical Economics, 44, 1129-1141. http://dx.doi.org/10.1007/s00181-012-0584-2

[35] Hamilton, J.D. and Flavin, M. (1986) On the Limitations of Government Borrowing: A Framework for Empirical Testing. The American Economic Review, 76, 808-819.

[36] International Monetary Fund (IMF) (2014). http://www.imf.org/en/Data

\section{Submit or recommend next manuscript to SCIRP and we will provide best service for you:}

Accepting pre-submission inquiries through Email, Facebook, LinkedIn, Twitter, etc. A wide selection of journals (inclusive of 9 subjects, more than 200 journals)

Providing 24-hour high-quality service

User-friendly online submission system

Fair and swift peer-review system

Efficient typesetting and proofreading procedure

Display of the result of downloads and visits, as well as the number of cited articles

Maximum dissemination of your research work

Submit your manuscript at: http://papersubmission.scirp.org/ 